\title{
The Role of Obesity in Predicting the Clinical Outcomes of COVID-19
}

\author{
Serdar Sahin ${ }^{a, b}$ Havva Sezer ${ }^{b, c}$ Ebru Cicek ${ }^{d}$ Yeliz Yagız Ozogul ${ }^{d}$ Murat Yildirim $^{d}$ \\ Tevhide Betul Icli ${ }^{d}$ Ozge Polat Korkmaz ${ }^{a, b}$ Emre Durcan ${ }^{a, b}$ Cem Sulu $^{a, b}$ Kayra Somay ${ }^{c}$ \\ Bahar Bekdemir $^{c}$ Sermin Borekcie ${ }^{\mathrm{e}}$ Dilek Yazici ${ }^{b, c}$ Oguzhan Deyneli ${ }^{b, c}$ Onder Ergonul ${ }^{f}$

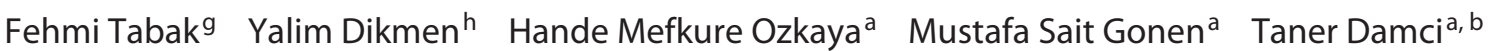 \\ Hasan Ilkova ${ }^{a, b}$ Volkan Demirhan Yumuk ${ }^{a, b}$

\begin{abstract}
aDivision of Endocrinology, Metabolism and Diabetes, Department of Internal Medicine, Cerrahpasa Medical Faculty, Istanbul University - Cerrahpasa, Istanbul, Turkey; ${ }^{\text {b} E u r o p e a n ~ A s s o c i a t i o n ~ f o r ~ t h e ~ S t u d y ~ o f ~ O b e s i t y ~-~ C o l l a b o r a t i n g ~}$ Center for Obesity Management, Istanbul, Turkey; ${ }^{C}$ Division of Endocrinology, Metabolism and Diabetes, Department of Internal Medicine, Koc University School of Medicine, Istanbul, Turkey; ${ }^{\text {dDepartment }}$ of Internal Medicine, Cerrahpasa Medical Faculty, Istanbul University - Cerrahpasa, Istanbul, Turkey; ${ }^{e}$ Department of Pulmonary Diseases, Cerrahpasa Medical Faculty, Istanbul University - Cerrahpasa, Istanbul, Turkey; fDepartment of Infectious Diseases and Clinical Microbiology, Koç University School of Medicine, Istanbul, Turkey; 9Department of Infectious Diseases and Clinical Microbiology, Cerrahpasa Medical Faculty, Istanbul University - Cerrahpasa, Istanbul, Turkey; hepartment of Anesthesiology and Reanimation, Cerrahpasa Medical Faculty, Istanbul University - Cerrahpasa, Istanbul, Turkey
\end{abstract}

\section{Keywords}

Obesity · Inflammatory markers - Respiratory support · COVID-19

\begin{abstract}
Introduction: The aim of this was to describe the predictors of mortality related to COVID-19 infection and to evaluate the association between overweight, obesity, and clinical outcomes of COVID-19. Methods: We included the patients $>18$ years of age, with at least one positive SARS-CoV-2 reverse transcriptase-polymerase chain reaction. Patients were grouped according to body mass index values as normal weight $<25 \mathrm{~kg} / \mathrm{m}^{2}$ (Group A), overweight from 25 to $<30$ $\mathrm{kg} / \mathrm{m}^{2}$ (Group B), Class I obesity 30 to $<35 \mathrm{~kg} / \mathrm{m}^{2}$ (Group C), and $\geq 35 \mathrm{~kg} / \mathrm{m}^{2}$ (Group D). Mortality, clinical outcomes, laboratory parameters, and comorbidities were compared among 4 groups. Results: There was no significant difference among study groups in terms of mortality. Noninvasive mechanical ventilation requirement was higher in group $B$
\end{abstract}

and $D$ than group $A$, while it was higher in Group $D$ than Group C (Group B vs. Group A [ $p=0.017]$, Group D vs. Group $A[p=0.001]$, and Group D vs. Group C $[p=0.016])$. Lung involvement was less common in Group A, and presence of hypoxia was more common in Group D (Group B vs. Group A [ $p=0.025]$, Group D vs. Group A [ $<0.001]$, Group D vs. Group B [ $p=0.006]$, and Group D vs. Group C [ $p=0.014])$. The hospitalization rate was lower in Group $A$ than in the other groups; in addition, patients in Group D have the highest rate of hospitalization (Group B vs. Group A [ $<0.001]$, Group C vs. Group A [ $<<0.001]$, Group D vs. Group A [ $p<$ 0.001], Group D vs. Group B [ $<<0.001]$, and Group D vs. Group C $[p=0.010])$. Conclusion: COVID-19 patients with overweight and obesity presented with more severe clinical findings. Health-care providers should take into account that people living with overweight and obesity are at higher risk for COVID-19 and its complications.

(c) 2021 The Author(s).

Published by S. Karger AG, Basel karger@karger.com www.karger.com/ofa

Karger $\stackrel{\text { ' }}{5}$

BOPEN ACCESS
(C) 2021 The Author(s)

Published by S. Karger AG, Basel

This is an Open Access article licensed under the Creative Commons Attribution-NonCommercial-4.0 International License (CC BY-NC) (http://www.karger.com/Services/OpenAccessLicense), applicable to the online version of the article only. Usage and distribution for commercial purposes requires written permission.
Correspondence to:

Volkan Demirhan Yumuk, vdyumuk@gmail.com 


\section{Introduction}

The World Health Organization declared a pandemic on March 11, 2020, and the first case of COVID-19 infection in Turkey was detected on March 10, 2020. Previous studies showed that COVID-19 mainly affects the respiratory system. However, current studies have reported that the cardiovascular system, liver, kidneys, and the coagulation system are affected as well as the respiratory system [1-4]. The clinical spectrum of COVID-19 ranges from asymptomatic disease to severe acute respiratory infection requiring intensive care unit (ICU). There are multiple risk factors related to mortality in patients with COVID-19. These factors include age, gender, diabetes mellitus, cerebrovascular, cardiovascular, and pulmonary diseases [5-7]. Among these factors, the highest mortality rate in COVID-19 patients was reported from patients with cardiovascular disease and diabetes mellitus [8]. The association between obesity and the above mentioned factors leading to the highest mortality is very powerful [9].

There is a tendency for respiratory dysfunction in people with obesity. This dysfunction is often associated with increased airway resistance, impaired gas exchange, reduced lung volume, and respiratory muscle strength. People with obesity are at increased risk for hypoventilation-related pneumonia, pulmonary hypertension, and cardiac stress [10]. In addition, obesity impairs immunity by deteriorating the cytokine response, resulting in a decrease in the cytotoxic cell response of immunocompetent cells [11]. Furthermore, in obesity molecules specific to adipose tissue may play a role in forming a favorable environment for immune-induced diseases [12].

Previous studies have reported the association between obesity and viral infections. In 2009, a significant percentage of hospital admissions and mortality due to H1N1 Influenza A virus infection was due to obesity [13, 14]. When considered in this context, obesity may increase the risk for COVID-19 infection and be associated with its worse prognosis. The primary end point of our study is the predictors of mortality related to COVID-19 infection. The secondary end points are hospitalization in ICU, need for noninvasive mechanical ventilation (NIMV), and invasive mechanical ventilation (IMV) in COVID-19 patients. We aimed to describe the predictors of mortality related to COVID-19 infection and to evaluate the association between overweight, obesity, and clinical outcomes of COVID-19.

\section{Material and Methods}

The study was approved by the local Ethics Committee of the Cerrahpasa Faculty of Medicine. The study adhered to the tenets of Helsinki. Written informed consent was obtained from all participants.

\section{Study Population}

This is a cross-sectional multicenter study involving COVID-19 patients who were admitted to COVID-19 outpatient clinics at the Cerrahpaşa Medical Faculty and Koç University School of Medicine Hospitals between March and August 2020. While patients with unstable vital signs (temperature, pulse, blood pressure, respiratory rate and oxygen saturation, and level of consciousness) and/or lung involvement were hospitalized, patients with normal vital signs and no pulmonary involvement were followed on an outpatient basis. Patients, over 18 years of age, with at least one positive SARS-CoV-2 reverse transcriptase-polymerase chain reaction (RT-PCR) examination were included. Cases without any positive RT-PCR examination and identified as "possible" or "probable" according to the Centers for Disease Control and Prevention were excluded [15]. Patients were classified according to their body mass index (BMI) in 4 categories as normal weight $<25 \mathrm{~kg} / \mathrm{m}^{2}$ (Group A), overweight $25-29.9 \mathrm{~kg} / \mathrm{m}^{2}$ (Group B), Class I obesity $30-34.9 \mathrm{~kg} / \mathrm{m}^{2}$ (Group C), and $\geq 35 \mathrm{~kg} / \mathrm{m}^{2}$ (Group D).

Computerized tomography (CT) imaging findings of patients were evaluated according to the criteria determined by the British Society of Thoracic Imaging [16]. Accordingly, classical (100\% compatible) and possible (71-99\% compatible) patterns were defined as COVID-19 lung involvement. Those with an indeterminate pattern ( $<70 \%$ compatible) and COVID-19 exclusion $(<70 \%$ compatible and with another diagnosis) were not considered to have COVID-19 lung involvement [16].

\section{SARS-CoV-2 Diagnosis}

Both oropharyngeal and nasopharyngeal swab samples were taken from the patients and RT-PCR test was performed. RNA was extracted with a commercial kit (BioSpeedy Nucleic Acid extraction kit; Bioeksen R \& D Technologies Ltd., Istanbul, Turkey), and detected COVID-19 RNA with a commercial RT PCR kit (BioSpeedy COVID-19 RT-qPCR kit; Bioeksen R \& D Technologies Ltd., Istanbul, Turkey) that targets the RdRP gene of COVID-19 in the samples. RT-PCR test protocol; 5 min RT-PCR at $52^{\circ} \mathrm{C}, 10-\mathrm{s}$ initial denaturation step at $95^{\circ} \mathrm{C}$, followed by 40 cycles of $1 \mathrm{~s}$ at $95^{\circ} \mathrm{C}$, and $30 \mathrm{~s}$ at $60^{\circ} \mathrm{C}$. The Rotor-Gene Q 5plex HRM platform was used for amplification and detection.

\section{Data Collection}

Demographic, clinical, laboratory, treatment, and outcome data were collected from digital medical records using a standardized data form. Data included gender, current age, smoking status, RT-PCR examination, CT findings, hospitalization, duration of hospitalization, comorbidities, NIMV need, IMV need, time between diagnosis and IMV, time between IMV and extubation, admission to ICU, time of stay in the ICU, acute complications during the COVID-19 process (acute renal failure, acute coronary syndrome, pulmonary embolism, and cerebrovascular disease [CVD]), death, duration of hospitalization, past medical history, weight, height, and laboratory test results on their first evaluation in the COVID outpatient clinic (white blood cell, lymphocyte, 
Table 1. Baseline demographics, comorbidities, and clinical data of patients

\begin{tabular}{lcr}
\hline & & $N^{*}$ \\
\hline Age (mean \pm SD), years & $50.9 \pm 17.0$ & 675 \\
Sex, $n$ (\%) & $312(47)$ & 675 \\
F & $363(53)$ & \\
M & $118(17.5)$ & 655 \\
Presence of hypoxia, $n(\%)$ & $437(64.7)$ & 655 \\
Lung involvement, $n$ (\%) & $116(21)$ & 555 \\
Current smokers, $n(\%)$ & $426(63)$ & 675 \\
Number of patients' hospitalization, $n(\%)$ & $54(8)$ & 675 \\
Number of patients hospitalized in the ICU, $n(\%)$ & $49(5.5)$ & 675 \\
Number of patients in need of NIMV, $n(\%)$ & $38(5.6)$ & 675 \\
Number of patients in need of intubation, $n(\%)$ & $16.8 \pm 16.0$ & 54 \\
Length of stay in the ICU (mean \pm SD), days & $12.3 \pm 10$ & 27 \\
Time between intubation and extubation (mean \pm SD), days & $10.3 \pm 9.7$ & 426 \\
Length of stay in the hospital, (mean \pm SD), days & $27.3 \pm 5.3$ & 648 \\
BMI (mean \pm SD), kg/m ${ }^{2}$ & & \\
Comorbidities & $162(25)$ & 648 \\
Obesity, $n(\%)$ & $46(6.8)$ & 675 \\
Malignancy, $n(\%)$ & $14(2.1)$ & 675 \\
Dementia, $n(\%)$ & $105(15.6)$ & 675 \\
T2DM, $n(\%)$ & $190(28.1)$ & 675 \\
Hypertension, $n(\%)$ & $48(7.1)$ & 675 \\
Dyslipidemia, $n(\%)$ & $73(10.8)$ & 675 \\
CVD, $n(\%)$ & $55(8.1)$ & 675 \\
COPD, $n(\%)$ & $16(2.4)$ & 675 \\
Asthma, $n(\%)$ & $50(8.1)$ & 675 \\
CRF, $n(\%)$ & $6(0.9)$ & 675 \\
Chronic hepatocellular disease, $n(\%)$ & $38(5.6)$ & 675 \\
Death, $n(\%)$ & & \\
\hline
\end{tabular}

ICU, intensive care unit; NIMV, noninvasive mechanical ventilation; BMI, body mass index; T2DM, type 2 diabetes mellitus; CVD, cardiovascular disease; COPD, chronic obstructive pulmonary disease; CRF, chronic renal failure. ${ }^{*}$ Number of patients whose information was available. platelet count, coagulation profile, creatinine, and liver function [aspartate aminotransferase and alanine aminotransferase] tests, ferritin, fibrinogen, CRP, procalcitonin, and saturation data).

\section{Statistical Analysis}

Distribution of variables was examined by using the Kolmogorov-Smirnov test. For the analysis of quantitative independent data, in normal distribution, we performed the ANOVA test, and in post hoc, the Bonferroni test was performed. In nonnormal distribution, we used the Kruskal-Wallis and Mann-Whitney U test for the analysis of quantitative-independent data Bonferroni correction was then performed to account errors due to the multiple comparisons among groups. Fisher's exact $\chi^{2}$ test was used for the analysis of qualitative independent data. Univariate and multivariate logistic regression analyses and estimated odds ratios (ORs) with $95 \%$ confidence intervals (CIs) were performed to determine the factors affecting mortality, ICU admission, intubation, and NIMV. In univariate analysis, age, male gender, BMI, presence of malignancy, dementia, type 2 diabetes (T2DM), hypertension, CVD, chronic obstructive pulmonary disease (COPD), chronic renal failure, and current smoking status were evaluated. Multivari- ate analyses were performed for factors that were significant at univariate analysis. Statistical significance was set as $p<0.05$ with confidence level of 95\%. Data were analyzed using Statistical Package for the Social Sciences v.22.0 software.

\section{Results}

Six hundred seventy-five patients with at least one positive SARS-CoV-2 RT-PCR test were evaluated. The mean age of the patients was $50.98 \pm 17.0$ years, and 312 (47\%) patients were female; 363 (53\%) patients were male. The BMI data of 27 (4\%) patients was missing. While there were 162 (25\%) people with obesity, 238 (36.7\%) patients were normal weight and 248 (38.2\%) were overweight in our study. Baseline demographics, comorbidities, and clinical data are shown in Table 1. During the SARS-CoV-2 infection 99 (14.7\%), patients devel- 
Table 2. The comparison of clinical and laboratory data of patients among Groups A-D

\begin{tabular}{|c|c|c|c|c|c|}
\hline & $\begin{array}{l}\text { Group A }(n: 238) \\
\left(<25 \mathrm{~kg} / \mathrm{m}^{2}\right)\end{array}$ & $\begin{array}{l}\text { Group B }(n: 248) \\
\left(25-29.9 \mathrm{~kg} / \mathrm{m}^{2}\right)\end{array}$ & $\begin{array}{l}\text { Group C }(n: 102) \\
\left(30-34.9 \mathrm{~kg} / \mathrm{m}^{2}\right)\end{array}$ & $\begin{array}{l}\text { Group D }(n: 60) \\
\left(\geq 35 \mathrm{~kg} / \mathrm{m}^{2}\right)\end{array}$ & $p$ value \\
\hline Age $($ mean $\pm \mathrm{SD})$, years & $45.4 \pm 18.3$ & $52.8 \pm 16.3$ & $54.7 \pm 14.3$ & $58.6 \pm 13.8$ & $<0.001$ \\
\hline \multicolumn{6}{|l|}{ Sex } \\
\hline $\mathrm{F}(\%)$ & $131(55)$ & $89(32.3)$ & $46(45.1)$ & $42(70)$ & \multirow[t]{2}{*}{$<\mathbf{0 . 0 0 1}$} \\
\hline $\mathrm{M}(\%)$ & $107(45)$ & $168(67.7)$ & $56(54.9)$ & $18(30)$ & \\
\hline \multicolumn{6}{|l|}{ Clinical parameters } \\
\hline Lung involvement, $n(\%)$ & $123(53.7)$ & $167(69)$ & $78(78)$ & $48(84.2)$ & $<\mathbf{0 . 0 0 1}$ \\
\hline Presence of hypoxia, $n(\%)$ & $28(12.2)$ & $48(19.8)$ & $19(19)$ & $21(38.8)$ & $<0.001$ \\
\hline Duration of hospitalization (mean $\pm \mathrm{SD}$ ), days & $9.7 \pm 11.6$ & $10.8 \pm 9.0$ & $10.4 \pm 10.1$ & $10.9 \pm 8.3$ & 0.183 \\
\hline Duration of stay in ICU (mean \pm SD), days & $17.4 \pm 24.3$ & $15.4 \pm 8.1$ & $31.3 \pm 22.2$ & $11.5 \pm 4.8$ & 0.047 \\
\hline Time intubation-extubation (mean \pm SD), days & $3.5 \pm 2.0$ & $4.5 \pm 3.1$ & $5.0 \pm 6.1$ & $4.4 \pm 2.9$ & 0.360 \\
\hline Current smoker, $n(\%)$ & $36(20)$ & $53(25.6)$ & $15(16.3)$ & $11(20)$ & 0.279 \\
\hline Hospitalization, $n(\%)$ & $109(45.8)$ & $161(64.9)$ & $77(75.5)$ & $55(91.7)$ & $<0.001$ \\
\hline NIMV, $n(\%)$ & $6(2.6)$ & $18(7.3)$ & $4(3.9)$ & $9(15.3)$ & 0.001 \\
\hline Intubation, $n(\%)$ & $11(4.7)$ & $16(6.5)$ & $6(5.9)$ & $4(6.7)$ & 0.839 \\
\hline ICU, $n(\%)$ & $14(6)$ & $24(9.7)$ & $6(5.9)$ & $9(15)$ & 0.082 \\
\hline Death, $n(\%)$ & $14(5.9)$ & $14(5.9)$ & $5(4.9)$ & $1(1.7)$ & 0.605 \\
\hline \multicolumn{6}{|l|}{ Laboratory parameters } \\
\hline $\mathrm{WBC}(\mathrm{mean} \pm \mathrm{SD}), 10^{3} / \mathrm{mm}^{3}$ & $9.0 \pm 43.2$ & $7.1 \pm 9.8$ & $6.6 \pm 2.3$ & $6.5 \pm 3.1$ & 0.818 \\
\hline Lymphocyte (mean \pm SD), $10^{3} / \mathrm{mm}^{3}$ & $1.3 \pm 0.6$ & $1.4 \pm 0.7$ & $1.5 \pm 0.7$ & $1.6 \pm 0.8$ & 0.111 \\
\hline $\mathrm{CRP}($ mean $\pm \mathrm{SD}), \mathrm{mg} / \mathrm{L}$ & $37.5 \pm 65.9$ & $38.7 \pm 52.6$ & $42.0 \pm 54.1$ & $44.7 \pm 49.4$ & $<\mathbf{0 . 0 0 1}$ \\
\hline Creatinine $($ mean $\pm \mathrm{SD}), \mathrm{mg} / \mathrm{L}$ & $1.00 \pm 1.1$ & $1.2 \pm 1.4$ & $1.03 \pm 0.7$ & $1.1 \pm 1.2$ & $<0.001$ \\
\hline Fibrinogen (mean $\pm \mathrm{SD}), \mathrm{mg} / \mathrm{L}$ & $428.6 \pm 153.0$ & $464.4 \pm 180.4$ & $423.5 \pm 141.1$ & $428.6 \pm 152.0$ & 0.445 \\
\hline Procalcitonin (mean \pm SD), ng/mL & $1.5 \pm 10.2$ & $0.1 \pm 0.4$ & $0.5 \pm 2.2$ & $0.2 \pm 0.9$ & 0.877 \\
\hline $\mathrm{AST}($ mean $\pm \mathrm{SD}), \mathrm{IU} / \mathrm{L}$ & $30.0 \pm 35.2$ & $32.0 \pm 20.1$ & $36.5 \pm 38.0$ & $32.2 \pm 17.2$ & $<\mathbf{0 . 0 0 1}$ \\
\hline $\operatorname{ALT}($ mean $\pm \mathrm{SD}), \mathrm{IU} / \mathrm{L}$ & $26.4 \pm 24.3$ & $29.2 \pm 22.8$ & $33.4 \pm 29.4$ & $28.6 \pm 19.5$ & 0.001 \\
\hline Ferritin (mean $\pm \mathrm{SD}), \mathrm{ng} / \mathrm{mL}$ & $416.7 \pm 898.3$ & $455.2 \pm 498.9$ & $532.2 \pm 1184.7$ & $273.1 \pm 290.7$ & 0.001 \\
\hline $\mathrm{D}$-dimer $($ mean $\pm \mathrm{SD}), \mathrm{mg} / \mathrm{L}$ & $1.6 \pm 4.9$ & $1.5 \pm 6.1$ & $1.2 \pm 3.8$ & $1.0 \pm 2.1$ & 0.364 \\
\hline
\end{tabular}

CRP, C-reactive protein; Hb, hemoglobin; WBC, white blood cell; AST, aspartate aminotransferase; ALT, alanine aminotransferase; ICU, intensive care unit; NIMV, noninvasive mechanical ventilation. Male patients: Group B versus Group A $(p<0.001)$, Group A versus Group D $(p=0.036)$, Group B versus Group D $(p<0.001)$, Group B versus Group C $(p=0.023)$, and Group C versus Group D ( $p=$ $0.002)$; age: Group B versus Group A $(p<0.001)$, Group C versus Group A $(p<0.001)$, and Group D versus Group A $(p<0.001)$; hospitalization: Group B versus Group A $(p<0.001)$, Group C versus Group A $(p<0.001)$, Group D versus Group A ( $p<0.001)$, Group D versus Group B $(p<0.001)$, and Group D versus Group C $(p=0.010)$; duration of ICU: Group C versus Group A ( $p=0.049)$; CRP: Group B versus Group A $(p=0.036)$, Group C versus Group A ( $p=0.017)$, and Group D versus Group A $(p=0.001)$; ferritin: Group C versus Group A $(p=0.031)$ and Group B versus Group A $(p=0.001)$; creatinine: Group C versus Group A ( $p=0.008)$, Group D versus Group A ( $p=0.013)$, and Group B versus Group A $(p<0.001)$; AST: Group B versus Group A $(p=0.001)$, Group D versus Group A ( $p$ $=0.037)$, and Group C versus Group A $(p=0.002)$; ALT: Group B versus Group A $(p=0.001)$, and Group C versus Group A $(p=0.03)$; NIMV: Group B versus Group A $(p=0.017)$, Group D versus Group A $(p=0.001)$, and Group D versus Group C ( $p=0.016)$; lung involvement: Group B versus Group A $(p=0.001)$, Group C versus Group A $(p<0.001)$, Group D versus Group A ( $p<0.001)$, and Group D versus Group B ( $p=0.022)$; presence of hypoxia: Group B versus Group A $(p=0.025)$, Group D versus Group A ( $p<0.001)$, Group D versus Group B $(p=0.006)$, and Group D versus Group C $(p=0.014)$.

oped acute kidney injury, 6 had acute coronary syndrome, 5 had pulmonary embolism, and 5 had CVD. The mean BMI of patients was $27.3 \pm 5.32 \mathrm{~kg} / \mathrm{m}^{2}$. Patient groups according to their BMIs' are as follows: Group A had 238 (36.7\%) patients; Group B had 248 (38.2\%) patients; Group C had 102 (15.7\%) patients; and Group D had 60 (9.2\%) patients. The comparison of clinical and laboratory parameters of patients are shown in Table 2.
The number of patients with lung involvement in terms of COVID-19 was significantly lower in normalweight patients than in overweight, obese patients with BMI $30-34.9 \mathrm{~kg} / \mathrm{m}^{2}$ and obese patients with $\mathrm{BMI} \geq 35$ (Group B vs. Group A [ $p=0.001]$, Group C vs. Group A $[p<0.001]$, and Group D vs. Group A $[p<0.001])$. In addition, in obese patients with BMI $\geq 35 \mathrm{~kg} / \mathrm{m}^{2}$, lung involvement was higher than in overweight patients (Group 
D vs. Group B [ $p=0.022])$. Also the number of patients presenting with low oxygen saturation was significantly higher in obese patients with BMI $\geq 35 \mathrm{~kg} / \mathrm{m}^{2}$ (Group D) $(p<0.001)$, who had the highest rate of hospitalization among the groups $(p<0.005)$. The lowest hospitalization rate was found in normal-weight patients (Group A) $(p<$ $0.005)$.

In our study, there was no significant difference among the groups in terms of mortality $(p=0.605)$. NIMV need was found to be significantly higher in Group B (25-30 $\left.\mathrm{kg} / \mathrm{m}^{2}\right)$ and $\mathrm{D}\left(\geq 35 \mathrm{~kg} / \mathrm{m}^{2}\right)$ than in Group $\mathrm{A}\left(<25 \mathrm{~kg} / \mathrm{m}^{2}\right)$ ( $p=0.017, p<0.001$, respectively). In addition, it was found to be significantly higher in Group $D$ than in Group C $\left(30-35 \mathrm{~kg} / \mathrm{m}^{2}\right)(p=0.016)$. ICU need was higher in Group D than in the other groups, although statistically not significant $(p=0.082)$. Furthermore, the length of stay in the ICU was significantly longer in Group C than in Group A ( $p=0.049)$. In addition, no significant difference was detected among groups in terms of time between diagnosis and intubation, hospitalization time, the time between intubation-extubation, and intubation need $(p=0.905, p=0.183, p=0.360$, and $p=0.839$, respectively).

When we evaluated the laboratory parameters, CRP levels were significantly lower in Group A than those in the other groups (Group B vs. Group A [ $p=0.036$ ], Group C vs. Group A [ $p=0.017]$, and Group D vs. Group A [ $p$ $=0.001])$. The ferritin level was found significantly higher in Group B and C than in Group A ( $p=0.001$ and $p=$ 0.031 , respectively). In contrast, there was no significant difference between the groups in terms of procalcitonin, white blood cell, lymphocyte, and fibrinogen levels. The comparison of clinical and laboratory parameters of patients are shown in Table 2.

In our study, it was observed that comorbidities were generally more common in patients with high BMI. Accordingly, dementia was found to be significantly higher in Group D than that in Group C (Group D vs. Group C $[p=0.049])$. Hypertension was the lowest in Group A and the highest in Group D (Group B vs. Group A [ $p<0.001$ ], Group C vs. Group A [ $p<0.001]$, Group D vs. Group A [ $p<0.001]$, Group D vs. Group B [ $p=0.002]$, and Group D vs. Group C [ $p=0.007]$ ). T2DM (Group C vs. Group A [ $p=0.001]$, Group D vs. Group A [ $p<0.001]$, Group D vs. B $[p<0.001]$, and Group D vs. Group C [ $p=0.003])$ and COPD (Group D vs. A [ $p=0.001]$, Group D vs. Group B $[p=0.003]$, and Group D vs. Group C [ $p=$ 0.041]) were detected the highest in Group D. Asthma was higher in Group C and D than in Group B (Group C vs. Group B [ $p=0.009]$ and Group D vs. Group B [ $p=$

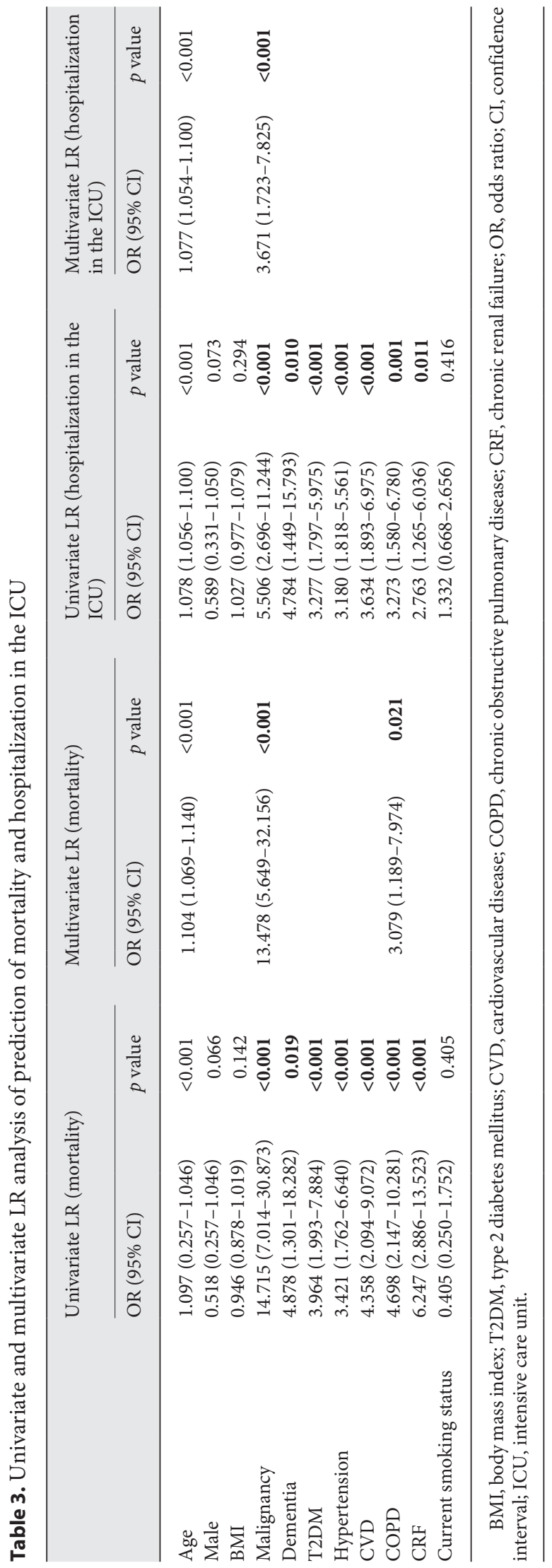

Obes Facts 2021;14:481-489

DOI: $10.1159 / 000517180$ 


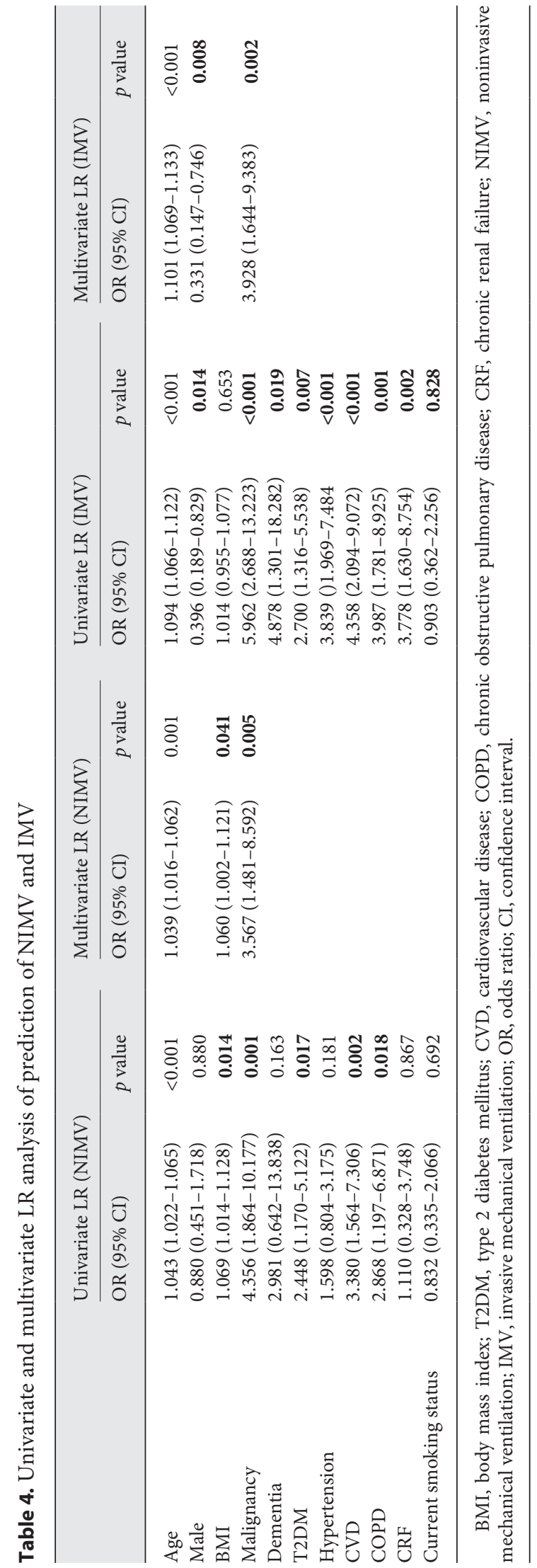

0.024]). While CVD was higher in Group B than in Group $C$, it was higher in Group D than in Group A (Group B vs. Group C $[p=0.007]$ and Group D vs. Group A [ $p=$ 0.010]).

According to the univariate and multivariate logistic regression, factors affecting mortality were as follows: age $(\mathrm{OR}=1.104 ; 95 \%$ CI $1.069-1.140, p<0.001)$, presence of malignancy $(\mathrm{OR}=13.478$; 95\% CI 5.649-32.156, $p<$ $0.001)$, and $\mathrm{COPD}(\mathrm{OR}=3.079 ; 95 \% \mathrm{CI} 1.189-7.974, p=$ $0.021)$. Factors affecting ICU admission were age $(\mathrm{OR}=$ 1.077 ; 95\% CI 1.054-1.100, $p<0.001)$, presence of malignancy $(\mathrm{OR}=3.671 ; 95 \%$ CI 1.723-7.825, $p<0.001)$, factors affecting intubation; age $(\mathrm{OR}=1.101 ; 95 \% \mathrm{CI} 1.069-$ $1.133, p<0.001)$, male gender $(\mathrm{OR}=0.331 ; 95 \%$ CI 0.147 $0.746, p=0.008)$, presence of malignancy $(\mathrm{OR}=3.928$; 95\% CI 1.644-9.383, $p=0.002$ ), factors affecting NIMV; age $(\mathrm{OR}=1.039 ; 95 \% \mathrm{CI} 1.016-1.062, p=0.001)$, BMI $(\mathrm{OR}=1.060 ; 95 \% \mathrm{CI} 1.002-1.121, p=0.041)$, and presence of malignancy $(\mathrm{OR}=3.567 ; 95 \% \mathrm{CI} 1.481-8.592$, $p$ $=0.005)$. Univariate and multivariate analyses of mortality and hospitalization in the ICU and univariate and multivariate analyses of IMV and NIMV are shown in Tables 3 and 4, respectively.

\section{Discussion}

We have demonstrated that obesity is an independent risk factor in patients with severe COVID-19. In this cross-sectional study, lung involvement and presence of hypoxia were more common in people living with obesity, and acute inflammatory markers were lower in normal-weight patients. Furthermore, hospitalization rate was higher, the duration of stay in the ICU was longer, and the need to NIMV was more frequent in people with obesity than those in the normal-weight patients.

When studies on the relationship between COVID-19 and obesity are evaluated, it is seen that the prevalence of overweight and obesity are high among COVID-19 patients $[17,18]$. In addition, a high frequency of obesity (47.5\%) was found among patients admitted to ICU for COVID-19 [19]. The results of our study were in line with the previous studies. The high prevalence of overweight and obesity in COVID-19 patients requires increased attention from health-care providers managing these patients [20]. Obesity was known to be a risk for hospitalization before the COVID-19 pandemic [14, 21]. These data have been confirmed in studies related to COVID-19 and obesity. Petrilli et al. [22] showed that people living with overweight and obesity needed hospitalization more fre- 
quently in patients with COVID-19. Our findings are consistent with the literature with regards to hospitalization being higher in patients with obesity than in nonobese patients.

Studies showed that obesity affected the mortality rate, viral titers in lung, and worsened lung pathology in viral infections $[13,23,24]$. The findings of studies on COVID-19 and obesity are also in line with these results [25]. In a study conducted by Luo et al. [26], the authors reported that people with obesity had a more severe lesion in lung than that in normal-weight patients. Furthermore, Kang et al. [27] showed that lung injury was more severe and disease progression was worse in people with obesity than in the patients without obesity. Although we did not classify the severity of lung involvement, lung injury was found to be higher in people with obesity in our study. In addition, it was observed that patients with lung involvement had a worse prognosis.

Busetto et al. [17] reported that people with overweight and obesity more frequently needed respiratory support and were more prone to be admitted to ICUs or semiICUs. In another study conducted by Simonnet et al. [19], it was seen that as BMI increased, the need for IMV increased, especially in patients with BMI $>35 \mathrm{~kg} / \mathrm{m}^{2}$. In addition, Frank et al. [18] showed that patients with higher BMI need for supplemental oxygen and have higher rates of intubation. Our findings are consistent with higher NIMV need and duration of stay in the ICU in patients with higher BMI. BMI was among the predictors for the need for NIMV in multivariate analysis. In addition, ICU admission was higher in patients with higher BMI although not reaching statistically significance.

Obesity is an important risk factor for comorbidities such as cardiovascular diseases, hypertension, and diabetes mellitus [10]. In a study conducted by Richardson et al. [28], the authors showed that the most common comorbidities among the hospitalized COVID-19 patients were hypertension and obesity. In another study, Zhou et al. [29] reported that hypertension was the most common comorbidity in patients with COVID-19 and followed by diabetes and coronary heart disease. Obesity-related comorbidities in obese patients with COVID-19 pose an additional risk of COVID-19 complications. The authors suggested that obesity-related comorbidities such as T2DM, hypertension, and cardiovascular diseases could increase the risk of mortality for COVID-19 in Italy [30]. Our results were found to be consistent with the literature.

The cumulative risk of mortality increases with obesity-related comorbidities [31]. Therefore, it is difficult to attribute mortality to obesity alone. There are variable results regarding obesity and mortality in the literature. For instance, Nie et al. [32] found that although pneumonia increased in obese and overweight patients, mortality did not increase. Likewise, in a study conducted by Chu et al. [33], patients with obesity were found to have a mortality rate of $30.85 \%$, while the mortality rate was found to be $33.05 \%$ in patients without obesity, and they reported that obesity was not associated with mortality. On the other hand, Ergönül et al. [25] showed that obesity is significantly associated with a higher case fatality rate. In our study, no association was found between mortality and $\mathrm{BMI}$ among groups in univariate and multivariate analysis due to the small numbers in each group. However, a significant association was found between mortality and age, malignancy, and COPD.

Exaggerated immune response to SARS-CoV-2 is one of the most important reasons for the severity of and the mortality from COVID-19 [34], and we know that obesity is a chronic subclinical inflammatory entity, and it can affect the immune responses to infectious diseases $[35,36]$. For instance, Chiappetta et al. [37] reported that interleukin (IL)-6 increased in obesity and positive correlation was found between CRP and waist-to-hip ratio in people with obesity. Serum amyloid-A is secreted by adipocytes and can activate macrophages to produce inflammatory cytokines (e.g., tumor necrosis factor]-a, IL-1 and IL-6, and resistin) $[38,39]$. Especially, IL-6 mediates the acute phase response and is a prognostic biomarker in sepsis and various acute organ damages [40]. Furthermore, IL-6 plays an important role in the pathogenesis of pulmonary diseases [40, 41]. In this respect, when looking into the literature, it can be seen that inflammatory markers are higher in obese COVID-19 patients [27, 42, 43]. In our study, inflammatory markers were found higher in people with obesity, which was in accordance with the current literature. Since our study was retrospective, we could not evaluate IL-6 levels. However, we know that IL-6 induces expression of CRP via acting on hepatocytes [44], so CRP may be an indirect indicator of IL-6.

Our study provides important data owing to a multicenter study investigating a large number of patients. However, there are several limitations to our study. First, our study has a retrospective design in which patients' data were collected from digital medical records. Second, we could not classify lung involvement radiologically, so we did not evaluate the association between the change in the severity of lung involvement and BMI. Third, at the early phase of the pandemic NIMV was the most frequently applied mode of respiratory support, and IMV 
was postponed to prevent adverse patient outcomes in ICU.

In conclusion, people with overweight and obesity having COVID-19 present with more severe clinical findings. As BMI increases, the need for respiratory support becomes more frequent, the risk for hospitalization is higher, and the ICU stay is longer. Therefore, health-care providers should take into account that people living with obesity are at higher risk for COVID-19 and its complications.

\section{Acknowledgments}

We are grateful to the zeal and courage of those frontline health-care providers who worked at the COVID-19 clinics at the Cerrahpaşa Medical Faculty Hospitals and Koç University Medical School Hospitals during the pandemic.

\section{Statement of Ethics}

The study was approved by the local Institutional Review Board, the Ethics Committee of the Cerrahpasa Faculty of Medicine, reference date and number: 08/07/2020-86136, and with the
1964 Helsinki declaration and its later amendments or comparable ethics standards. Written informed consent was obtained from all participants.

\section{Conflict of Interest Statement}

The authors declare that they have no conflicts of interest.

\section{Funding Sources}

This research did not receive any specific grant from funding agencies in the public, commercial, or not-for-profit sectors. The European Association for the Study of Obesity shall cover the journal service fee.

\section{Author Contributions}

V.D.Y., D.Y., S.B., Ö.E., Y.D., and S.Ş. drafted the manuscript. S.Ş., H.S., E.Ç., Y.Y.O., M.Y., T.B.İ., Ö.P.K., E.D., C.S., K.S., and B.B. collected the data. V.D.Y., D.Y., S.B., Ö.E., Y.D., and S.S. conducted all analyses. O.D., F.T., H.M.Ö., M.S.G., T.D., and H.I. contributed to drafts of the manuscript. All the authors approved the final version of the article.

\section{References}

1 Han H, Xie L, Liu R, Yang J, Liu F, Wu K, et al. Analysis of heart injury laboratory parameters in 273 COVID-19 patients in one hospital in Wuhan, China. J Med Virol. 2020 Jul; 92(7):819-23.

2 Zhang C, Shi L, Wang FS. Liver injury in COVID-19: management and challenges. Lancet Gastroenterol Hepatol. 2020 May;5(5):42830.

3 Durvasula R, Wellington T, McNamara E, Watnick S. COVID-19 and kidney failure in the acute care setting: our experience from $\mathrm{Se}$ attle. Am J Kidney Dis. 2020 Jul;76(1):4-6.

4 Dolhnikoff M, Duarte-Neto AN, de Almeida Monteiro RA, da Silva LFF, de Oliveira EP, Saldiva PHN, et al. Pathological evidence of pulmonary thrombotic phenomena in severe COVID-19. J Thromb Haemost. 2020 Jun; 18(6):1517-9.

$5 \mathrm{Li} \mathrm{X}, \mathrm{Xu} \mathrm{S}$, Yu M, Wang K, Tao Y, Zhou Y, et al. Risk factors for severity and mortality in adult COVID-19 inpatients in Wuhan. J Allergy Clin Immunol. 2020 Jul;146(1):110-8.

6 Du RH, Liang LR, Yang CQ, Wang W, Cao TZ, Li M, et al. Predictors of mortality for patients with COVID-19 pneumonia caused by SARSCoV- 2: a prospective cohort study. Eur Respir J. 2020 Sep 24;56(3):2002961.

7 Kang YJ. Mortality rate of infection with COVID-19 in Korea from the perspective of un- derlying disease. Disaster Med Public Health Prep. 2020 Jun;14(3):384-6.

$8 \mathrm{Wu}$ Z, McGoogan JM. Characteristics of and important lessons from the Coronavirus Disease 2019 (COVID-19) outbreak in China. JAMA. 2020 Apr 7;323(13):1239-42.

9 GBD 2015 Obesity Collaborators. Health effects of overweight and obesity in 195 countries over 25 years. New Engl J Med. 2017 Jul 6;377(1):13-27.

10 Stefan N, Birkenfeld AL, Schulze MB, Ludwig DS. Obesity and impaired metabolic health in patients with COVID-19. Nat Rev Endocrinol. 2020 Jul;16(7):341-2.

11 Rojas-Osornio SA, Cruz-Hernández TR, Drago-Serrano ME, Campos-Rodríguez R. Immunity to influenza: impact of obesity. Obes Res Clin Pract. 2019 Sep-Oct;13(5):419-29.

12 Karagiannides I, Pothoulakis C. Obesity, innate immunity and gut inflammation. Curr Opin Gastroenterol. 2007 Nov;23(6):661-6.

13 Louie JK, Acosta M, Samuel MC, Schechter R, Vugia DJ, Harriman K, et al. A novel risk factor for a novel virus: obesity and 2009 pandemic influenza a $(\mathrm{H} 1 \mathrm{~N} 1)$. Clin Infect Dis. 2011 Feb 1;52(3):301-12.

14 Moser JAS, Galindo-Fraga A, Ortiz-Hernández AA, Gu W, Hunsberger S, Galán-Herrera JF, et al. Underweight, overweight, and obesity as independent risk factors for hospital- ization in adults and children from influenza and other respiratory viruses. Influenza Other Respir Viruses. 2019 Jan;13(1):3-9.

15 European Centre for Disease Prevention and Control. Case definition for coronavirus disease 2019 (COVID-19), as of 29 May 2020 [Internet]. European Centre for Disease Prevention and Control - Surveillance; 2020.

16 BSTI. Thoracic imaging in COVID-19 infection. Guidance for the Reporting Radiologist British Society of thoracic imaging [Version 2, 2020 March 16]. Available from: https:// www.bsti.org.uk/media/resources/files/ BSTI_COVID19_Radiology_Guidance_version_2_16.03.20.pdf.

17 Busetto L, Bettini S, Fabris R, Serra R, Dal Pra C, Maffei P, et al. Obesity and COVID-19: an Italian Snapshot. Obesity. 2020 Sep;28(9): $1600-5$.

18 Frank RC, Mendez SR, Stevenson EK, Guseh JS, Chung M, Silverman MG. Obesity and the risk of intubation or death in patients with coronavirus disease 2019. Crit Care Med. 2020 Nov;48(11):e1097-101.

19 Simonnet A, Chetboun M, Poissy J, Raverdy V, Noulette J, Duhamel A, et al. High prevalence of obesity in Severe Acute Respiratory Syndrome Coronavirus-2 (SARS-CoV-2) requiring invasive mechanical ventilation. Obesity. 2020 Jul;28(7):1195-9. 
20 Frühbeck G, Baker JL, Busetto L, Dicker D, Goossens GH, Halford JCG, et al. European association for the study of obesity position statement on the Global COVID-19 pandemic. Obes Facts. 2020 Apr;13(2):292-6.

21 Morgan OW, Bramley A, Fowlkes A, Freedman DS, Taylor TH, Gargiullo P, et al. Morbid obesity as a risk factor for hospitalization and death due to 2009 pandemic influenza A(H1N1) disease. PLoS One. 2010 Mar 15; 5(3):e9694.

22 Petrilli CM, Jones SA, Yang J, Rajagopalan H, O'Donnell L, Chernyak Y, et al. Factors associated with hospital admission and critical illness among 5279 people with coronavirus disease 2019 in New York City: prospective cohort study. BMJ. 2020 May 22;369:m1966.

23 Honce R, Karlsson EA, Wohlgemuth N, Estrada LD, Meliopoulos VA, Yao J, et al. Obesity-related microenvironment promotes emergence of virulent influenza virus strains. mBio. 2020 Mar 3;11(2):e03341-19.

24 Dicker D, Bettini S, Farpour-Lambert N, Frühbeck G, Golan R, Goossens G, et al. Obesity and COVID-19: the two sides of the coin Obes Facts. $2020 \mathrm{Jul} ; 13(4): 430-8$.

25 Ergönül Ö, Akyol M, Tanriöver C, Tiemeier $\mathrm{H}$, Petersen E, Petrosillo N, et al. National case fatality rates of the COVID-19 pandemic. Clin Microbiol Infect. 2020 Jan;27(1):118-24

26 Luo X, Jiaerken Y, Shen Z, Wang Q, Liu B, Zhou H, et al. Obese COVID-19 patients show more severe pneumonia lesions on CT chest imaging. Diabetes Obes Metab. 2020 Jan;23(1):290-3.

27 Kang Z, Luo S, Gui Y, Zhou H, Zhang Z, Tian $\mathrm{C}$, et al. Obesity is a potential risk factor contributing to clinical manifestations of $\mathrm{CO}$ VID-19. Int J Obes. 2020 Dec;44(12):247985.
28 Richardson S, Hirsch JS, Narasimhan M, Crawford JM, McGinn T, Davidson KW, et al. Presenting characteristics, comorbidities, and outcomes among 5700 patients hospitalized with COVID-19 in the New York City Area. JAMA. 2020 May 26;323(20):2052-9.

29 Zhou F, Yu T, Du R, Fan G, Liu Y, Liu Z, et al. Clinical course and risk factors for mortality of adult inpatients with COVID-19 in Wuhan, China: a retrospective cohort study. Lancet. 2020 Mar 28;395(10229):1054-62.

30 Muscogiuri G, Pugliese G, Barrea L, Savastano S, Colao A. Obesity: the "Achilles heel" for COVID-19? Metabolism. Clin Exp. 2020 Jul; 108:154251.

31 Hussain A, Mahawar K, Xia Z, Yang W, ELHasani S. Obesity and mortality of COVID 19. Meta-analysis. Obes Res Clin Pract. 2020 Jul-Aug; 14(4):295-300.

32 Nie W, Zhang Y, Jee SH, Jung KJ, Li B, Xiu Q. Obesity survival paradox in pneumonia: a meta-analysis. BMC Med. 2014 Apr 10;12:61.

33 Chu Y, Yang J, Shi J, Zhang P, Wang X. Obesity is associated with increased severity of disease in COVID-19 pneumonia: a systematic review and meta-analysis. Eur J Med Res. 2020 Dec 2;25(1):64

34 Mehta P, McAuley DF, Brown M, Sanchez E, Tattersall RS, Manson JJ. COVID-19: consider cytokine storm syndromes and immunosuppression. The Lancet. 2020 Mar 28; 395(10229):1033-4.

35 Wadhwa PD, Buss C, Entringer S, Swanson JM. Developmental origins of health and disease: brief history of the approach and current focus on epigenetic mechanisms. Semin Reprod Med. 2009 Sep;27(5):358-68.

36 Jirtle RL, Skinner MK. Environmental epigenomics and disease susceptibility. Nat Rev Genet. 2007 Apr;8(4):253-62.
37 Chiappetta S, Sharma AM, Bottino V, Stier C. COVID-19 and the role of chronic inflammation in patients with obesity. Int J Obes. 2020 Aug;44(8):1790-2.

38 Tilg $\mathrm{H}$. The role of cytokines in non-alcoholic fatty liver disease. Dig Dis. 2010 May;28(1): 179-85.

39 Tilg H, Moschen AR. Adipocytokines: mediators linking adipose tissue, inflammation and immunity. Nat Rev Immunol. 2006 Oct;6(10): $772-83$

40 Voiriot G, Razazi K, Amsellem V, Tran Van Nhieu J, Abid S, Adnot S, et al. Interleukin-6 displays lung anti-inflammatory properties and exerts protective hemodynamic effects in a double-hit murine acute lung injury. Respir Res. 2017 Apr 19;18(1):64.

41 Peters MC, McGrath KW, Hawkins GA, Hastie AT, Levy BD, Israel E, et al. Plasma interleukin-6 concentrations, metabolic dysfunction, and asthma severity: a cross-sectional analysis of two cohorts. Lancet Respir Med. 2016 Jul;4(7):574-84.

42 Zhang JJ, Dong X, Cao YY, Yuan YD, Yang YB, Yan YQ, et al. Clinical characteristics of 140 patients infected with SARS-CoV-2 in Wuhan, China. Allergy. 2020 Jul;75(7):173041.

43 Han W, Quan B, Guo Y, Zhang J, Lu Y, Feng $\mathrm{G}$, et al. The course of clinical diagnosis and treatment of a case infected with coronavirus disease 2019. J Med Virol. 2020 May;92(5): 461-3.

44 Gudowska-Sawczuk M, Wrona A, Gruszewska E, Cylwik B, Panasiuk A, Flisiak R, et al. Serum level of interleukin-6 (IL-6) and N-terminal propeptide of procollagen type I (PINP) in patients with liver diseases. Scand J Clin Lab Invest. 2018 Feb-Apr;78(1-2):125-30. 